\title{
DYNAMIC STATE OF ECOSYSTEM CARRYING CAPACITY UNDER ISLAND URBANIZATION: A CASE STUDY OF PINGTAN ISLAND IN THE SOUTHEASTERN COAST OF CHINA
}

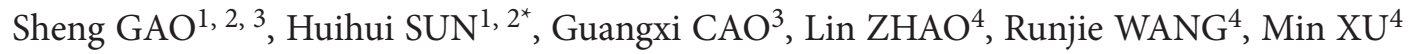 \\ ${ }^{1}$ Institute of Natural Resources and Environmental Audits, Nanjing Audit University, Nanjing, \\ 211815 Jiangsu, China \\ ${ }^{2}$ School of Government Audit, Nanjing Audit University, Nanjing, 211815 Jiangsu, China \\ ${ }^{3}$ School of Management Science and Engineering, Nanjing university of information science and technology, \\ Nanjing, 210044 Jiangsu, China \\ ${ }^{4}$ School of Geographic Science, Nanjing Normal University, Nanjing, 210023 Jiangsu, China
}

Received 09 April 2018; accepted 10 December 2018

\begin{abstract}
The assessment of ecological environment during the large-scale development of islands is a major topic in the study of current coastal islands. Choosing the appropriate assessment method to evaluate the suitability of carrying capacity of islands and making relevant suggestions are significant to the sustainable development of islands. Ecological footprint method is used to analyze the ecological carrying capacity of Pingtan Island (PI) from 2005 to 2016 for promoting the coordinated rational development and construction and ecological environment of the island. Although PI is in rapid urban development and construction, the island maintains secure and stable ecological conditions. PI is used as a research case to analyze the sustainable development of the ecological environment through the carrying capacity of the island ecosystem.
\end{abstract}

Keywords: ecological carrying capacity, ecological footprint, ecological security, sustainable development, urbanization, island ecology.

\section{Introduction}

The status of ecological carrying capacity is a major research topic at home and abroad, but the ecological carrying capacity of islands under rapid urbanization has been rarely explored. The analysis of ecological carrying capacity aims to describe the supporting role of ecosystems in the economic activities of humans and to provide early warning of specific environmental or resource factors from a sustainable perspective for maintaining the healthy state of balance of ecosystems (Dai, Nan, \& Liu, 2010; Cheng, Fu, Meng, Li, \& Pei, 2018). The methods of ecological carrying capacity analysis are divided into the following categories: logistic equation method, resource supply and demand balance method (Liu \& Borthwick, 2011), ecological footprint method, energy analysis, Miami model (net primary productivity model of vegetation), resource difference method (Peng, Wang, Li, \& He, 2014) state space method, index system method of sustainable development, system model (statistical and system dynamic models), multi-objective programming model (Sun, Chen, \& Tian, 2018), and spatial decision support system. Shi et al. (2016) obtained the carrying capacity of islands on the basis of ecosystems. The author highlighted South Miaodao Islands' basic carrying capacity and carrying capacity index and established the relevant evaluation model to comprehensive explore the sustainable development of the islands. Ma et al. (2017) proposed a general conceptual model to systematically evaluate Dongtou Islands' marine ecosystem carrying capacity and developed an indicator system. The general conceptual model of system evaluation of marine ecosystem carrying capacity is proposed, which includes the identification of carrier, the determination of carrier object, and the construction of evaluation index frame. Shi, Hutchinson, and Xu (2004) established a sustainability indicator system based on three subsystems of environment and resources, economic development, and society. The author also evaluated the sustainable development of the coastal areas in Shanghai and Chongming Island (Changjiang Estuary). This system method is feasible and valid. Wei, Guo, Wu, and Ye (2014) developed the conceptual model of "driving force-pressure-state -response-control." An index system

*Corresponding author. E-mail: 320277@nau.edu.cn 
of regional comprehensive carrying capacity and its rate of change is constructed to support the assessment of longterm sustainable development of regional economy on the basis of the Nantong coastal area.

Urbanization is a process of social and economic change, including the non-agriculturalization of agricultural population, the continuous expansion of urban population, the continuous expansion of urban land to the suburbs, the increasing number of cities, and the process of urban social, economic, and technological changes entering the countryside. In urbanizing islands under rapid development and construction, the ecological carrying capacity of the islands should be considered and their ecological footprint diversity index and ecosystem sustainable development capacity should be monitored. Timely adjusts the development planning and policies of islands to ensure the ecological security of island-based cities. The ecological footprints of PI and the supply of ecological capacity are compared to explain whether the pressure of human activities on the island ecosystem is within the range of ecological carrying capacity provided by the region. Accordingly, the safety state of the system can be determined and the development planning and policy management can be adjusted timely. Ultimately, the sustainable development of the island and its environment can be promoted. The large-scale development and construction of PI can be designed appropriately with a dynamic state analysis of its ecological carrying capacity. The dynamic characteristics of PI's ecological security under rapid urbanization are revealed. The results provide scientific decision-making basis for the construction of PI's eco-city, enrich island- related research cases, and provide references for future works.

\section{Study area and materials}

PI is located in the southeast coast of China $\left(25^{\circ} 16^{\prime} \mathrm{N}-25^{\circ} 44^{\prime} \mathrm{N}, 119^{\circ} 32^{\prime}-120^{\circ} 10^{\prime} \mathrm{E}\right)$. The island is located in the subtropical zone of maritime monsoon climate. The annual average temperature is $19.0^{\circ} \mathrm{C}-19.9^{\circ} \mathrm{C}$, the annual rainfall is $900-1200 \mathrm{~mm}$, the average annual evaporation is $1917.4 \mathrm{~mm}$, and the average annual water resource is $1.72 \times 108 \mathrm{~m}^{3}$. The total area of the island is $267.13 \mathrm{~km}^{2}$, which is two times the size of Xiamen Island and more than half of the size of Singapore. The island is the largest island in Fujian Province (Figure 1). The island is also composed of plains with low elevation. With the establishment of Pingtan Comprehensive Experimental Zone in 2009, the plan is to build a pilot zone for crossstrait exchange and cooperation pilot projects and a pilot zone for coordinated economic and social development in the west side of the Taiwan Straits. An emerging eco-livable island city can be established on the west coast of the straits. The island gradually becomes an important window for mainland China's economic, trade, and humanistic exchanges with Taiwan. PI is expected to develop into a new livable island city on the west side of the Taiwan Strait with a population of 1 million. The infrastructure

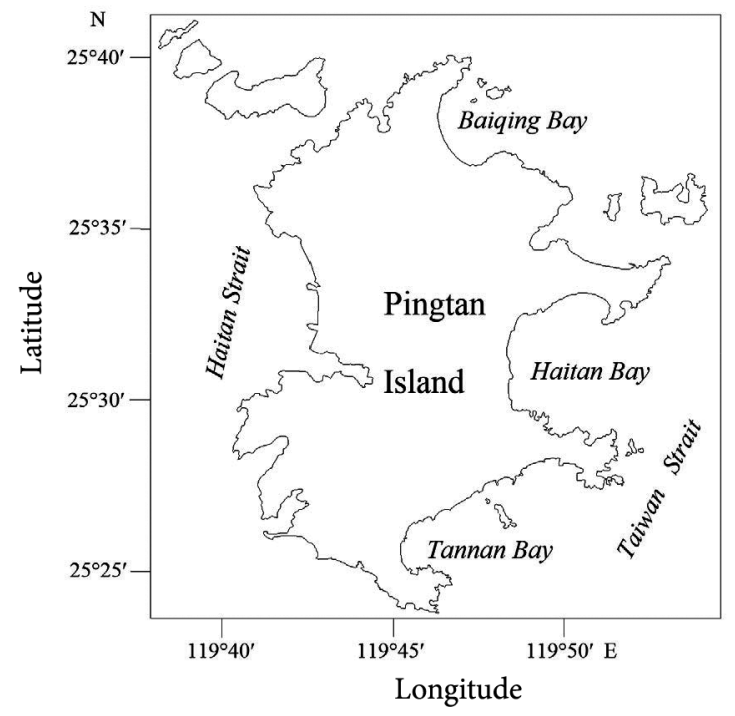

Figure 1. Geographic location of Pingtan Island

and urbanization of the island have rapidly developed. However, the dramatic increase in human activities has significantly impacted the ecological environment of the island, thereby exacerbating its ecological vulnerability. The increase in urban population has significantly impact the ecological carrying capacity and sustainable development of the island.

This study focuses on PI before entering into China Free Trade Zone construction of ecological carrying capacity. The primary data required are mainly from Pingtan County Statistical Yearbook and Fuzhou City Social Economic Survey Data. The consumption data and land use data of PI for biological and energy resources are all from Fujian Province Statistical Yearbook from 2005 to 2016 and Fuzhou City Statistical Yearbook from 2005 to 2016. Annual gross grain output, total grain sown area, various land types, and global average yields of consumption patterns are based on the UN's Food and Agriculture Organization (FAO) basic database and China Rural Statistical Yearbook.

On the basis of the specific conditions of Fujian Province and PI, the actual production of various land types in PI is calculated to determine the yield factor. In particular, the total output of food is the island divided by the sown area of food crop. The annual output of agricultural products is divided by the global average grain yield. PI's farmland per year yield factors mainly include crop area and sown non-food crops. The area is the sown area of food crops. Given that construction land basically occupies arable land or may become arable land, the production factor of land for construction is the same as that of arable land. The sum of freshwater area, seawater culture area, and sea area of PI is taken as the water area of the island. The sum of freshwater aquaculture, mariculture, and marine fishing is taken as the output of aquatic products. The average yield per unit of water area is divided by the average global water yield to obtain the water yield factors. 
The forest yield factor is calculated as the net increase in output per unit area of logs. The grassland yield in PI is determined by dividing the average yield of grassland in China by the grassland yield factor obtained from the average yield of grassland in the world in combination with the actual situation of PI. The average of the commonly used equilibrium factors in the world as an equilibrium factor (Wackernagel \& Rees, 1998; Rashid et al., 2018). Determines the equilibrium factors of cultivated land, forest land, grassland, construction land, water area, and fossil energy land.

\section{Methods}

\subsection{Ecological footprint demand}

\subsubsection{Biological consumption model}

The calculation of ecological footprint project is divided into two categories of biological resource consumption and energy consumption. Consumer items in each category are also divided. The resources and energy that will be consumed are converted into various types of bioproductive land area. Then, the area of bio-productive land occupied for the production of the ith consumption item is obtained using the annual consumption of the $i$ th consumption item over the annual production of the $i$ th consumption item. The annual consumption of the $i$ th consumption item in a certain area can be calculated by consumption $=$ output + import - export.

$$
\begin{aligned}
& E F_{1}=N \times \sum_{i=1}^{n}\left(a_{i} \times r_{j}\right)=N \times \sum_{i=1}^{n}\left(\frac{c_{i}}{p_{i}} \times r_{j}\right)= \\
& N \times \sum_{i=1}^{n}\left(\frac{\left(Q_{i}+I_{i}-E_{i}\right.}{p_{i}} \times r_{j}\right) ; \\
& (i=1,2,3,4, \cdots, n) ; \\
& e f=E F_{1} / N .
\end{aligned}
$$

In Formula (1) and (2), $E F_{1}$ is the total ecological footprint of regional biological data. ai is the area of bio-productive land per capita ( $\mathrm{hm}^{2} / \mathrm{cap}$ ) occupied for the production of the ith consumption item. $r_{j}$ is the equilibrium factor of $j$ types of bio-productive land. $i$ is the type of consumer item. $c_{i}$ is the annual consumption of the $i$ th consumer item. $p_{i}$ is the annual average global production of the $i$ th consumption item. $Q_{i}$ is the annual per capita production of the $i$ th consumption item. $L_{i}$ is the annual per capita imports of the $i$ th consumption item. $E_{i}$ is the annual per capita exports of the $i$ th consumption item. $e f$ is the per capita ecological footprint of regional biological data. $N$ is the number of people participating in the consumption.

\subsubsection{Energy consumption model}

Wackernagel and Rees (1998) provided the average calorific value per unit area of fossil fuel production in the world and the corresponding conversion factor table (Chen, 2017). On this basis, the units of energy consumption project statistic data converted into a certain area of fossil fuels are calculated as follows:

$$
\begin{aligned}
& E F_{2}=\sum_{k=1}^{n}\left(a f_{k} \times r_{j}\right)=\sum_{k=1}^{n}\left\{\left[\left(c_{k} \times w_{k}\right) / a e_{k}\right] \times r_{j}\right\}, \\
& (k=1,2,3,4, \cdots, n) .
\end{aligned}
$$

In Formula (3), $E F_{2}$ is the total ecological footprint of regional energy data consumption. $a f_{k}$ is the per capita fossil energy land area occupied by the $k$ th energy consumption after conversion, that is, the per capita ecological footprint of the $k$ th energy consumption project. $r_{j}$ is the equilibrium factor of $j$ types of bio-productive land. $k$ is for certain types of energy consumption projects. $C_{k}$ is the per capita consumption of the $k$ th energy project. $w_{k}$ is the conversion factor for the $k$ th energy project. $a e_{k}$ is the global average energy footprint for the $k$ th energy project, that is, the average heat output per unit area of fossil fuels in the world $\left(\mathrm{GJ} / \mathrm{hm}^{2}\right)$.

\subsection{Ecological carrying capacity}

Ecological carrying capacity is also known as ecological footprint supply (Song, Li, Semakula, \& Zhang, 2015). The annual yield of six types of land products and the annual ecological footprint and ecological carrying capacity are calculated using the annual production of various types of agricultural products in Pingtan County and the average global production of PI. The calculation is some type of ecological capacity per capita = some type of biological productive land area $\times$ equilibrium factor $\times$ yield factor.

$$
\begin{aligned}
& E C=N \times e c=N \times \sum_{j=1}^{6}\left(a_{j} \times r_{j} \times y_{j}\right), \\
& (j=1,2,3,4, \cdots, n) .
\end{aligned}
$$

In Formula (4), EC is the total ecological carrying capacity of the region $\left(\mathrm{hm}^{2}\right) . N$ is the population. $j$ is the area of bio-productive land area. ec is the ecological capacity per capita $\left(\mathrm{hm}^{2} / \mathrm{cap}\right) . a_{j}$ is the actual possession of a certain type of biological productive land per capita. $r_{j}$ is the equilibrium factor. $y_{j}$ is the yield factor.

\subsection{Ecological surplus or ecological deficit}

The ecological footprint provided by ecosystems of a region and the ecological footprints of the population in the region are compared by:

Ecological surplus $($ or deficit $)=$

Ecological carrying capacity - Ecological footprint.

If $E F>E C$, then the ecological surplus exists. In other words, the pressure on the ecosystem in the region is within the ecological carrying capacity provided by the region. The ecosystem in the area is safe and can be considered a region of sustainable socio-economic development. If $E F<E C$, then an ecological deficit exists. Therefore, the demand for products and services provided by the ecosystems of the region to the people in the region exceeds their supply. The ecosystems in the area are unsafe, and 
the economic development in the area can be considered unsustainable.

\subsection{Regional ecological tension index model}

Ecological stress index refers to the ratio of per capita ecological footprint and ecological carrying capacity of renewable resources in a country or region. This ratio represents the degree of pressure on regional ecological environment.

$$
e n=\frac{e f}{e c} \text {. }
$$

In Formula (6), en is the ecological tension index and is also called ecological pressure. $e f$ is the per capita ecological footprint of renewable resources in the region. $e c$ is the per capita ecological carrying capacity of regional renewable resources.

\subsection{Regional ecologica safety index model}

The model of regional ecological security is the ratio of the difference between ecological carrying capacity and per capita ecological footprint to the carrying capacity (Wang et al., 2012). This ratio comprehensively reflects the status of ecological security from the perspective of carrying capacity.

$$
E I=\frac{e c-e f}{e c}=1-e n
$$

When $E I>0$, ecologica safety index shows ecological surplus. In other words, the human pressure on the natural system is within the range of ecological carrying capacity provided by the region. Large value indicates large ecological surplus and high ecological value of the region. If an area presents $E l<0$, an ecological deficit exists. Therefore, the human demand for products and services provided by the natural systems in the area is beyond the ecological carrying capacity of this area, that is, the ecological security in the area is in an unsafe state. Low ecological value indicates the area is unsafe.

\subsection{Sustainable development capability analysis}

Using the formula to evaluate the development capability of the system, the diversity of eco-economic systems

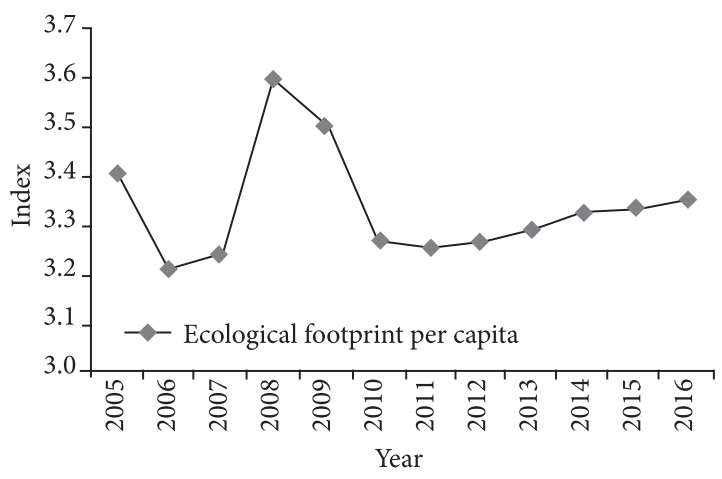

Figure 2. Variation trend of ecological footprint per capita can be measured by the area of different land types in the calculation of ecological footprint.

$$
P=H \times e f=-\sum\left(q_{i} \ln q_{i}\right) \times e f .
$$

In Formula (8), $P$ is the system capacity for sustainable development. $H$ is the ecological footprint diversity index. ef is the per capita ecological footprint. $q_{i}$ is the proportion of the ecological footprint per capita of the $i$ th type of land in the total per capita ecological footprint. The greater the absolute value of $p$, the safer the sustainable development of the ecosystem in the region. On the contrary, the less secure.

\section{Results and analysis}

\subsection{Dynamic trend and analysis of ecological footprint}

Following Wackernagel and Rees (1998) and other determined global unit of fossil fuel production area of the average heat and the corresponding conversion factor, the amounts of biological resource consumption and energy consumption are classified by land type and the ecological footprint of each year is obtained. The results show that water area significantly impacts the per capita ecological footprint of PI and that the trend of the two is the same.

\subsection{Dynamic trend and analysis of ecological carrying capacity}

The area of six land types is multiplied by their respective yield and equilibrium factors to obtain the ecological carrying capacity of various land types in PI. The previous calculation of ecological carrying capacity of Pingtan County is assessed to ensure the reliability of the results. After deducting the influence of $12 \%$ of the protected area of biodiversity, the ecological carrying capacity of PI for each year can be obtained. The results show that water area significantly contributes to the per capita ecological carrying capacity of PI and that the trend of both is the same. In particular, aquaculture and fishing play a decisive role on the carrying capacity of the island. The per capita ecological carrying capacity of cultivated land decreases. By contrast, the per capita carrying capacity of four land use types of grassland, forest land, construction

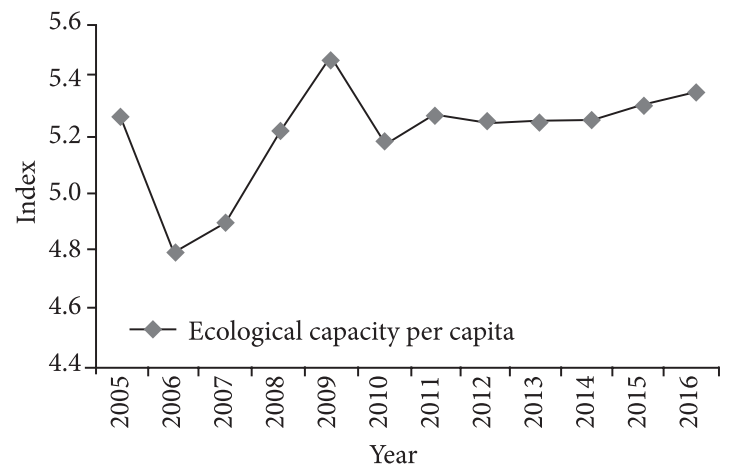

Figure 3. Variation trend of ecological capacity per capita 
Table 1. Multiple ecosystem status index of Pingtan Island

\begin{tabular}{|l|c|c|c|c|c|}
\hline Year & Ecological surplus & $\begin{array}{c}\text { Ecological } \\
\text { pressure index }\end{array}$ & $\begin{array}{c}\text { Ecological } \\
\text { security index }\end{array}$ & $\begin{array}{c}\text { Ecological footprint } \\
\text { diversity index }\end{array}$ & $\begin{array}{c}\text { Sustainable development } \\
\text { capability of ecosystem }\end{array}$ \\
\hline 2005 & 1.8707 & 0.6453 & 0.3547 & 0.5884 & 2.0029 \\
\hline 2006 & 1.5979 & 0.6679 & 0.3321 & 0.5654 & 1.8170 \\
\hline 2007 & 1.6684 & 0.6601 & 0.3399 & 0.5758 & 1.8659 \\
\hline 2008 & 1.6299 & 0.6880 & 0.3120 & 0.5745 & 2.0649 \\
\hline 2009 & 1.9761 & 0.6392 & 0.3608 & 0.6060 & 2.1214 \\
\hline 2010 & 1.9246 & 0.6295 & 0.3705 & 0.6476 & 2.1174 \\
\hline 2011 & 2.0311 & 0.6157 & 0.3843 & 0.6870 & 2.2351 \\
\hline 2012 & 1.9994 & 0.6201 & 0.3799 & 0.6806 & 2.2210 \\
\hline 2013 & 1.9743 & 0.6248 & 0.3752 & 0.6807 & 2.2384 \\
\hline 2014 & 1.9478 & 0.6306 & 0.3694 & 0.6768 & 2.2501 \\
\hline 2015 & 1.9826 & 0.6271 & 0.3729 & 0.6777 & 2.2592 \\
\hline 2016 & 2.0107 & 0.6250 & 0.3750 & 0.6779 & 2.2715 \\
\hline
\end{tabular}

land, and fossil energy land is stable. From the dynamic change tendency of ecological capacity per capita in PI (Figure 3), the per capita ecological carrying capacity of PI is found to present a decreasing trend only in the periods of 2005-2006 and 2009-2010 but an increasing trend in the periods of 2006-2008 and 2010-2016.

\subsection{Ecological surplus, ecological tension index, and ecologica safety index}

Using the obtained per capita ecological carrying capacity and per capita ecological footprint of PI in each year,

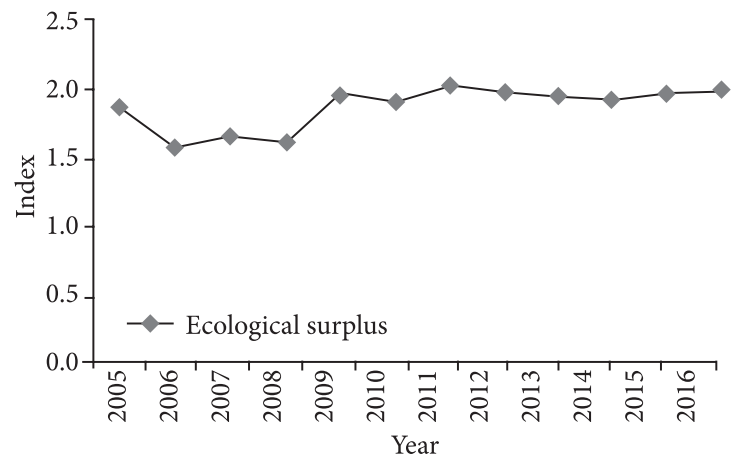

Figure 4. Variation trend of ecological surplus

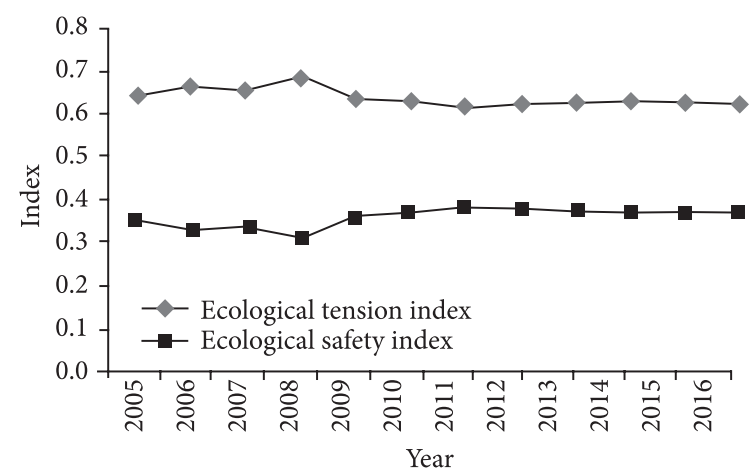

Figure 5. Variation trend of ecological tension index and ecologica safety index ecological surplus, ecological tension index, and ecological safety index are calculated (Table 1).

The results show that the per capita ecological carrying capacity of PI is larger than the per capita ecological footprint. The overall trend of ecological surplus in all the evaluation years is stable (Figure 4). The island development from 2008 to 2011 shows that the development and construction of the island have developed the ecological environment quality. The ecological tension index is stable first and then declines (Figure 5). The ecologica safety index increases steadily and reflects the steady improvement in PI's ecological security.

\subsection{Sustainability analysis}

The diversity of eco-economic system is estimated on the basis of the area of different land types in the calculation of ecological footprint (Table 1).

The results show that the diversity index of ecological footprint in PI increases steadily (Figure 6). This increase indicates that the changes in the types of bio-productive land use in ecological footprint in recent years have been stable. The diversity index increases from 2005 to 2011, but keeps stable from 2011 to 2016. The ecosystem development capacity of the island is also stable (Figure 7).

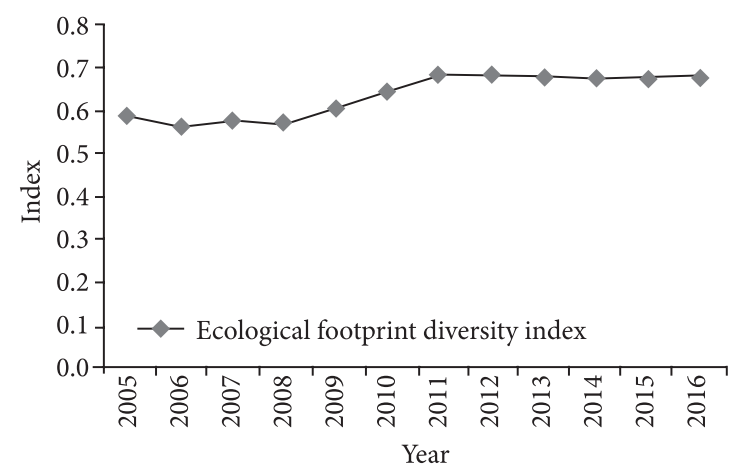

Figure 6. Variation trend of ecological footprint diversity index 


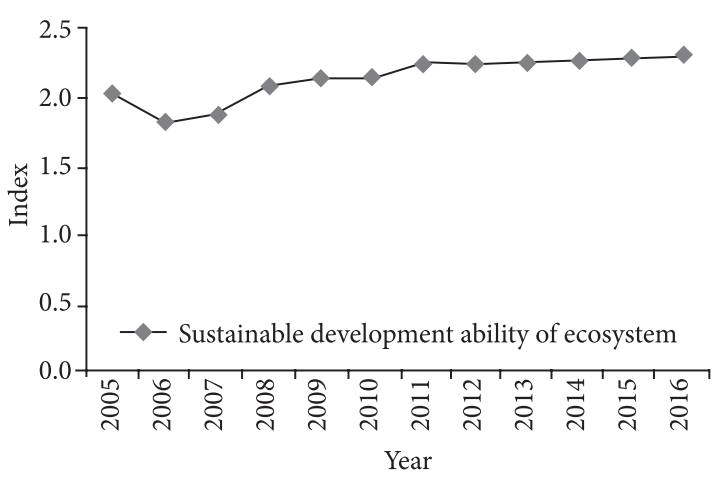

Figure 7. Variation trend of sustainable development capability of ecosystem

Therefore, the rapid development and construction of the island have not damaged the ecological environment. In the future development, the use of all types of land should be balanced and the efficiency and diversity of land use and the diversity of ecological footprint should be improved.

\section{Discussion}

PI in China has gradually developed with the increase in population and the expansion of human activities. The government has focused on the ecological security of the country, especially the ecological security of the island because of its risky situation. The isolation of the island from the mainland by its geographical location has greatly restricted its natural conditions (Wang et al., 2012). The already fragile environment of the island becomes vulnerable to man-made damage with the constant influence of human activities. Thus, building a healthy and sustainable development model for its environmental protection is necessary. Rational resource exploitation and utilization and ecological environment protection of the island should be conducted under urbanization (Fan et al., 2017).

Since the introduction of the principle of ecological footprint by Canadian scholar Wackernagel and Rees (1998) in 1992, this method has been widely used to evaluate the sustainable development of ecological environment. This study evaluates the dynamic trend of ecological carrying capacity of islands by comparing ecological footprint and supply and demand. Whether the pressure exerted by humans exceeds the carrying capacity is determined, the relationship between human needs and ecological carrying capacity is obtained, the safety status of the ecological environment of islands is revealed, and distance safety goals are provided for tradeoff. The innovation of this research lies in summarizing the research results of all the equilibrium factors around the world and avoiding the uncertainty of the equilibrium factor in the evaluation area (H.-S. Chen, C.-Y. Chen, Chang, \& Hsieh, 2017).

The calculation of ecological footprint in PI in this study mainly includes two parts, namely, biological resource consumption and energy consumption. The calculation ignores the estimation of trade adjustment. The consumption of different items in all years is converted into the area of bio-productive land to provide such consumption. The amounts of biological resource consumption and energy consumption of all years are classified by land type to obtain the per capita ecological footprint of each year.

The consumption of biological resource projects mainly includes major consumer items, such as agricultural products, livestock products, aquatic products, fruits, and timber. Grain, oil, vegetables, melons, and pork belong to the arable land. Grain is further divided into varieties of rice, wheat, sweet potato, potato, grains, soybeans, and beans. Beef, lamb, milk, and eggs are attributed to grass. Fruits belong to woodland. Marine and freshwater products are attributed to water, and the amounts of marine and freshwater products are combined. The raw data for the global average yields of the various consumer products used are based on the UN's FAO (Fang, Heijungs, \& De Snoo, 2015). The global average output of food, vegetables, and fruits can be found directly in the database. The global average yield per unit area of indirect agricultural products (e.g., pork and poultry) needs to be adjusted using the conversion factor from food conversion. According to Wackernagel and Rees (1998), the conversion coefficient from grain to pork is 6 . Thus, the global average yield per unit area of pork and poultry is equal to the global average output of grain divided by 6 . The global average output of aquatic products is obtained by the global average annual output of aquatic products divided by the global water area, which can be found directly from the World Food Database.

The energy consumption items used in this study mainly include coal, coke, crude oil, fuel oil, gasoline, kerosene, diesel, liquefied petroleum gas, heat, and electricity. No trade adjustment is required because the consumption data recorded in the Statistical Yearbook are used for energy consumption projects. Following China's energy conversion coefficient of the energy consumption converted into a unified energy unit and the global unit of fossil fuel production area of the average heat as a standard, the energy consumption is converted into the corresponding fossil fuel land area on the basis of the formula of ecological footprint.

First, six types of bio-productive land, namely, arable land, forest land, grassland, construction land, water area, and fossil fuel land (Ye, Chou, L. Yang, S. Yang, \& Du, 2014), are used to calculate the existing six types of bioproductive land area in the island. Second, these types of bio-productive land are multiplied by an equalization factor to equalize them and convert them into those with the global average productivity of bio-productive land. The average area of such bio-productive land is obtained by the equilibrium factor for a given type of bio-productive land area in a given country equals the average global production of such bio-productive land area divided by the average production volume of all types of bio-productive land in the world (Liang et al., 2015). Third, the ecological carrying capacity of a certain type of biological productive 
land in the area is multiplied by the average area of various types of global bio-productive land by the local production factor (Wang \& Xu, 2015). The yield factor for a given type of bio-productive land in a country or region is the ratio of the average production of a certain type of bioproductive land in the country or region to the average production of similar types of land in the world. Finally, $12 \%$ of the ecological conservation capacity of the calculated ecological carrying capacity is the ecological footprint available to mankind.

\section{Conclusions}

First, water area presents the largest share of ecological footprint per capita and ecological capacity per capita among the six land types on PI. The per capita ecological footprint of arable land, forest land, and fossil energy land in each evaluation year is larger than the per capita ecological carrying capacity. The per capita ecological footprint of grassland is slightly higher than that of per capita ecological carrying capacity, which is nearly flat. However, the per capita ecological footprint of water area and construction land is significantly below the per capita ecological carrying capacity.

Second, the overall trend of per capita ecological footprint and per capita ecological carrying capacity in PI during each evaluation year is stable. The per capita ecological footprint is between 3.2137 and 3.5945, and the per capita ecological carrying capacity is between 4.8116 and 5.4766. However, the per capita ecological carrying capacity in each year is higher than the per capita ecological footprint, thereby resulting in ecological surplus. In other words, the pressure on PI's ecosystem is within the range of ecological carrying capacity provided by the island. The ecosystem in the area is in a safe state. The socio-economic development at Tam Island is within the scope of sustainability. The overall trend of ecological surplus is stable at a range of 1.5979-2.0311. Specifically, the ecological surplus index is stable since 2009. The highest ecological surplus is 2.0311 in 2011 and is 2.0107 in 2016. The ecological surplus values in 2006 and 2008 are smaller at 1.5979 and 1.6299 , respectively, than those in other years.

Third, the overall trend of ecological tension index in PI in each evaluation year is stable at a range of $0.6157-$ 0.6880 . Therefore, the ratio of per capita ecological footprint to ecological carrying capacity of PI's renewable resources is small, and the pressure on the island ecological environment is in a normal state. The overall trend of ecologica safety index is stable at a range of $0.3120-0.3843$. Therefore, the human pressure on the natural systems in this area is within the ecological carrying capacity provided by the island, and the ecological status of PI is safe.

Fourth, the general trend of ecological footprint diversity index in PI during all the evaluation years is stable at a range of 0.5654-0.6870. In other words, the changes caused by various types of bio-productive land use in the ecological footprint in recent years have been stable. The overall trend of sustainable development of ecosystems is stable. In particular, a steady increase range of 1.81702.2715 is observed since 2012. Therefore, the rapid development and construction of the island have not damaged the ecological environment.

\section{Acknowledgments}

This work is supported by the Jiangsu Social Science Fund (No. 19GLC013); Youth teacher research and development project of Nanjing Audit University (No. 19QNPY019); Jiangsu Social Science Fund (No. 17GLB003); A Project Funded by the Priority Academic Program Development of Jiangsu Higher Education Institutions; Major Program of the Philosophy and Social Science Fund of Education Department of Jiangsu Province (No. 2017ZDAXM005). The authors are very grateful to the anonymous reviewers for reading our manuscript and for providing suggestions.

\section{References}

Chen, H.-S. (2017). Evaluation and analysis of eco-security in environmentally sensitive areas using an emergy ecological footprint. International Journal of Environmental Research Public Health, 14(2), 136.

https://doi.org/10.3390/ijerph14020136

Chen, H.-S., Chen, C.-Y., Chang, C.-T., \& Hsieh, T. (2014). The construction and application of a carrying capacity evaluation model in a national park. Stochastic Environmental Research and Risk Assessment, 28(6), 1333-1341.

https://doi.org/10.1007/s00477-013-0844-5

Cheng, K., Fu, Q., Meng, J., Li, T. X., \& Pei, W. (2018). Analysis of the spatial variation and identification of factors affecting the water resources carrying capacity based on the cloud model. Water Resources Management, 32(8), 2767-2781. https://doi.org/10.1007/s11269-018-1957-x

Dai, F., Nan, L., \& Liu, G. (2010). Assessment of regional ecological security based on ecological footprint and influential factors analysis: a case study of Chongqing Municipality, China. International Journal of Sustainable Development and World Ecology, 17(5), 390-400. https://doi.org/10.1080/13504509.2010.500074

Fan, J., Wang, Y., Ouyang, Z., Li, L., Xu, Y., Zhang, W., Wang, C., $\mathrm{Xu}$, W., Li, J., Yu, J., \& Zhou, K. (2017). Risk forewarning of regional development sustainability based on a natural resources and environmental carrying index in China. Earths Future, 5(2), 196-213.

https://doi.org/10.1002/2016EF000490

Fang, K., Heijungs, R., \& De Snoo, G. R. (2015). Understanding the complementary linkages between environmental footprints and planetary boundaries in a footprint-boundary environmental sustainability assessment framework. Ecological Economics, 114, 218-226. https://doi.org/10.1016/j.ecolecon.2015.04.008

Liu, R. Z., \& Borthwick, A. G. L. (2011). Measurement and assessment of carrying capacity of the environment in Ningbo, China. Journal of Environmental Management, 92(8), 2047-2053. https://doi.org/10.1016/j.jenvman.2011.03.033

Liang, S. K., Pearson, S., Wu, W., Ma, Y. J., Qiao, L. L., Wang, X. H., Li, J. M., \& Wang, X. L. (2015). Research and integrated coastal zone management in rapidly developing 
estuarine harbours: a review to inform sustainment of functions in Jiaozhou Bay, China. Ocean \& Coastal Management, $116,470-477$.

https://doi.org/10.1016/j.ocecoaman.2015.09.014

Ma, P., Ye, G., Peng, X., Liu, J., Qi, J., \& Jia, S. (2017). Development of an index system for evaluation of ecological carrying capacity of marine ecosystems. Ocean \& Coastal Management, 144, 23-30.

https://doi.org/10.1016/j.ocecoaman.2017.04.012

Peng, W., Wang, X. M., Li, X., \& He, C. (2014). Sustainability evaluation based on the emergy ecological footprint method: A case study of Qingdao, China, from 2004 to 2014. Ecological Indicators, 85, 1249-1261. https://doi.org/10.1016/j.ecolind.2017.12.020

Rashid, A., Irum, A., Malik, I. A., Ashraf, A., Liu, R., Liu, G., Ullah, H., Ali, M. U., \& Yousaf, B. (2018). Ecological footprint of Rawalpindi; Pakistan's first footprint analysis from urbanization perspective. Journal of Cleaner Production, 170, 362-368. https://doi.org/10.1016/j.jclepro.2017.09.186

Shi, C., Hutchinson, S. M., \& Xu, S. (2004). Evaluation of coastal zone sustainability: an integrated approach applied in shanghai municipality and Chong Ming Island. Journal of Environmental Management, 71(4), 335-344. https://doi.org/10.1016/j.jenvman.2004.03.009

Shi, H., Shen, C., Zheng, W., Li, F., Wang, X., Chi, Y., Guo, Z., Qiao, M., Gao, L., \& Ding, D. (2016). A model to assess fundamental and realized carrying capacities of island ecosystem: A case study in the southern Miaodao Archipelago of China. Acta Oceanologica Sinica, 35(2), 56-67. https://doi.org/10.1007/s13131-016-0808-y

Song, G., Li, M., Semakula, H. M., \& Zhang, S. (2015). Food consumption and waste and the embedded carbon, wa- ter and ecological footprints of households in China. Science of the Total Environment, 529, 191-197.

https://doi.org/10.1016/j.scitotenv.2015.05.068

Sun, C., Chen, L., \& Tian, Y. (2018). Study on the urban state carrying capacity for unbalanced sustainable development regions: Evidence from the Yangtze River Economic Belt. Ecological Indicators, 89, 150-158.

https://doi.org/10.1016/j.ecolind.2018.02.011

Wackernagel, M., \& Rees, W. (1998). Our ecological footprint: reducing human impact on the earth (Vol. 9). Canada: New Society Publishers.

Wang, H., Wang, H., Sun, H., Wang, X., Liao, X., Chen, Z., \& Li, $X$. (2012). Assessment of the ecological security in the three gorges reservoir area by using the ecological footprint method. Journal of Mountain Science, 9(6), 891-900. https://doi.org/10.1007/s11629-012-2445-Z

Wang, T., \& Xu, S. (2015). Dynamic successive assessment method of water environment carrying capacity and its application. Ecological Indicators, 52, 134-146.

https://doi.org/10.1016/j.ecolind.2014.12.002

Wei, C., Guo, Z., Wu, J., \& Ye, S. (2014). Constructing an assessment indices system to analyze integrated regional carrying capacity in the coastal zones - A case in Nantong. Ocean \& Coastal Management, 93, 51-59.

https://doi.org/10.1016/j.ocecoaman.2014.02.009

Ye, G., Chou, L. M., Yang, L., Yang, S., \& Du, J. (2014). Evaluating the performance of integrated coastal management in Quanzhou, Fujian, China. Ocean \& Coastal Management, 96, $112-122$

https://doi.org/10.1016/j.ocecoaman.2014.05.010 